\title{
STUDY OF A NEW TYPE OF FLETTNER ROTOR IN MERCHANT SHIPS
}

\author{
Boyang $\mathrm{Li}^{1}$ \\ Rui Zhang ${ }^{1}$ \\ Yajing $\mathrm{Li}^{1}$ \\ Baoshou Zhang ${ }^{2^{*}}$ \\ Chao Guo ${ }^{1}$ \\ ${ }^{1}$ College of Electromechanical Engineering, Qingdao University of Science and Technology, Qingdao, Shandong, China \\ ${ }^{2}$ School of Aerospace Engineering, Tsinghua University, Beijing, China \\ *Corresponding author: sxsdzbs@126.com (B. Zhang)
}

\begin{abstract}
Wind energy is a clean and renewable source of energy. This study seeks to explore the potential for utilising wind power for merchant ships. A new type of Flettner rotor (rotating cylinder) mounted on the superstructure of a ship is proposed and numerically simulated. The construction and installation of the rotating cylinder is designed and a numerical simulation of the ship-mounted cylinder is carried out, using the commercially available CFD code Ansys Fluent to obtain parameters such as lift and drag coefficient of the cylinder in different conditions. Specifically, it is found that the cylinder type superstructure can play a certain role in reducing the effect of friction by comparing traditional and cylindrical superstructures; the rotating cylinder can generate auxiliary thrust for the ship. After analysis, the wind speed around the cylinder and spin ratio will have a direct influence on its thrust effect; there is an inflection point in the lift coefficient with the increase of $\alpha$; the thrust coefficient (8.63) reaches the maximum environmental wind speed at $10 \mathrm{~m} / \mathrm{s}$ and spin ratio is 2.5 . For the rotating cylinder, the greater the environmental wind, the greater the thrust contribution generated under the same spin ratio conditions. The maximum thrust can reach 750,000 N; the cylinder's auxiliary propulsion contribution shows a better advantage in $\alpha=2.0$. The effective power generated by the cylinder reaches a maximum of 2,240 $\mathrm{kW}$ for environmental wind speed $=20 \mathrm{~m} / \mathrm{s}$ and $\alpha=1.0$.
\end{abstract}

Keywords: Ship propulsion; Flettner rotor; Wind energy; Rotating cylinder; Numerical simulation

\section{INTRODUCTION}

Due to the increased volume of seaborne cargo transactions around the world, the number of merchant ships is increasing. Ships not only consume a large amount of fuel during a voyage but they also produce exhaust gas, polluting the environment by burning fuel. In order to reduce harmful emissions from ships and promote the application of new cleaner energy, IMO puts forward higher requirements for emissions from ships. "Green ship" has become the current trend in the development of the ship industry and it is has become urgent to find new, alternative clean energy [1-3]. Wind energy is a kind of renewable energy with the advantages of abundant reserves, wide distribution and pollution-free $[4,5]$. The wind energy over the ocean is more abundant because the sea is open and wind friction is small. There are great advantages for the application of wind energy to ships sailing in the ocean.

In terms of wind energy utilisation by ships, scholars at home and abroad have carried out many related studies, including: traditional sails, Flettner rotor auxiliary propulsion, kite auxiliary propulsion, and airfoil sail auxiliary propulsion [6-9]. Among them, the Flettner rotor is a reasonable system, regarding the utilisation of wind energy on ships. It has a history of more than one hundred years of research. This kind of rotor propulsion is usually called "Flettner rotors". The first time such equipment was installed on a ship was in the early 1920s. Flettner rotors are mainly installed on the deck of a ship. One side of the Flettner rotors forms a low pressure area and the other side forms a high pressure area, so that it can generate lift (like a sail) to boost the ship, also known as the Magnus effect. 


\begin{tabular}{|ll|ll|}
\hline Nomenclature & & & \\
$D$ & Diameter of cylinder & $C_{L}$ & Lift coefficient \\
$H$ & Height of cylinder & $C_{T}$ & Thrust coefficient \\
$A$ & Cross-sectional area of cylinder & $C_{D}$ & Drag coefficient \\
$\rho$ & Fluid density & $C_{H}$ & Heel coefficient \\
$v$ & Kinematic viscosity is $1.45^{*} 10-5 \mathrm{~Pa} / \mathrm{s}$ & $C_{f}$ & Friction coefficient \\
$V_{\text {ship }}$ & Ship speed & $T$ & Thrust \\
$V_{\text {en. }}$ & Environmental wind speed & $P_{T}$ & Thrust power \\
$V_{a}$ & Apparent wind speed & $C_{M}$ & Moment coefficient \\
$\operatorname{Re}=\frac{V_{a} * D}{v}$ & Reynolds number & $P_{\text {motor }}$ & Power consumption \\
$U_{\tan }$ & Tangential velocity of cylinder & $P_{e f}$ & Effective power \\
$\alpha=\frac{U_{\tan }}{V_{a}}$ & Spin ratio & $p_{\infty}$ & Static pressure \\
$\omega$ & Angular velocity of rotating cylinder & $C_{p}=\frac{p-p_{\infty}}{0.5 * \rho *} V_{a}^{2}$ & Pressure coefficient \\
$y+$ & A non-dimensional wall distance & & \\
\hline
\end{tabular}

Flettner rotors have been installed on some ships around the world and have been put into practical use. In 1924-1926, the German ship Buckau first installed a rotor device and conducted a sailing test, as shown in Fig. 1(a). An interesting example is the fact that the wind energy company Enercon launched a Flettner-driven cargo ship, named "E-Ship 1". Compared with traditional cargo ships of the same size, in 2010 the Flettner rotors on "E-ship 1" (developed by Enercon) saved as much as $25 \%$ of the fuel that would normally be used (https://www.evwind.es/2013/07/30/enercon-rotorsail-ship-e-ship-1-saves-up-to-25-fuel/34733). Since its maiden voyage in 2010, E-Ship 1 (developed for transporting Enercon wind turbine components) has covered more than 170,000 sea miles, as shown in Fig. 1(b). Then, in November 2014, a 9,700 ton ro-ro ship "Estraden" (owned by the Finnish shipping company Bore) adopted Norsepower's Flettner rotor plan. The ship sailed back and forth between the Netherlands and the United Kingdom, potentially saving 5\% of fuel, as shown in Fig. 1(c). In January 2018, the 6,400 ton bulk carrier "Afros" (customised by the Greek shipowner Victoria Steamship) installed four Flettner rotors. In April 2018, Flettner rotors were installed on the "Viking Grace," owned by Viking Cruises; they were $24 \mathrm{~m}$ high and $4 \mathrm{~m}$ in diameter, and it became the world's first passenger ship using Flettner rotors technology. There are also practical applications of Flettner rotors on oil tankers. In August 2018, Maersk announced that two Flettner rotors, with a height of $30 \mathrm{~m}$ and a diameter of $5 \mathrm{~m}$, were installed on an L2 tanker. This is the largest Flettner rotor in a practical application so far, as shown in Fig. 1(d).
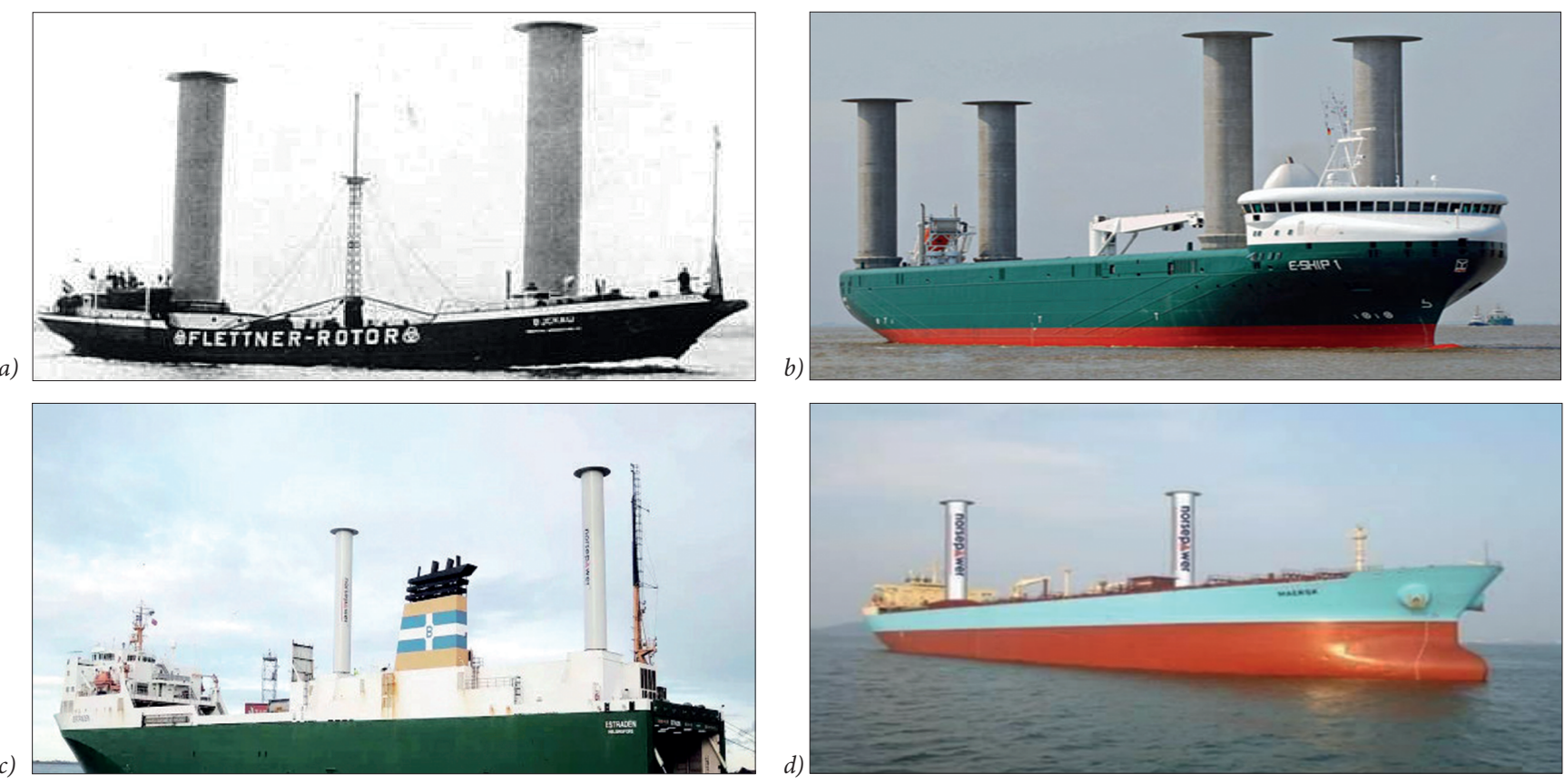

Fig. 1. Flettner rotors in actual applications 
There are also many practical cases in the application of Flettner rotors on medium and large merchant ships. Flettner rotors have become effective aids for ship navigation. Many experiments and numerical simulations have also been carried out on the utilisation of Flettner rotors to achieve ship propulsion. Bordogna et al. [10] studied a series of large wind tunnel tests on Flettner rotors, with the aim of better understanding the effect of the Reynolds number on the aerodynamic performance of Flettner rotors and, for aerodynamic performance, a velocity ratio of 2.5 was a key point. Marco et al. [11-13] assessed the impact of aspect ratio, spin ratio and end plate diameter on Flettner rotor performance; endplates installed on the Flettner rotor had a good effect. In reference [14], the relative position and velocity ratio of two Flettner rotors were tested and the conclusion was drawn that the velocity ratio and relative position were the decisive factors determining the influence of aerodynamic interaction on the performance of Flettner rotors. The flow structures with different Reynolds Numbers and different spin rates were discussed. Laminar and turbulence flow models were compared by Karabelas et al. [15]. Craft et al. [16] proposed that a superstructure disc on the rotors can result in a slight increase in the lift coefficient at high RPM. Traut et al. [17] studied numerical models of two wind power technologies, Flettner rotors and a towing kite, and proposed a technical method for evaluating the contribution of wind energy to ship propulsion, applying it to five different shipping routes. Salter pointed out a way of using Flettner rotors to achieve high-lift coefficients and high lift-drag ratios [18]. A study of a rotating cylinder with an endplate was conducted by Badalamenti and Prince [19], where spinning and stationary endplates were considered. The results of the study show that, although the endplate can significantly enhance the lift and improve the lift-to-drag ratio, the ultimate lift coefficient is always reached regardless of the endplate conditions.

According to the conditions generated by the Magnus effect, the magnitude of the Magnus force not only depends on the wind speed and the angular velocity of the Flettner rotors, but it is also affected by the wind-receiving area of the Flettner rotors. For Flettner rotors using the Magnus effect, a larger wind-receiving area produces greater boosting force [20-23]. In order to use wind energy more effectively and produce better boosting effects for ships, most Flettner rotors are installed in pairs on ships. The diameter range of the cylinder is between $1.5 \mathrm{~m}$ and $5 \mathrm{~m}$, the height range is $15 \mathrm{~m}$ to $40 \mathrm{~m}$ and, in general, the number of Flettner rotors is 2 to $6[24,25]$. However, a large number of Flettner rotor installations will increase the additional load capacity of the ship and will also occupy the ship's deck space. Installing multiple cylinders will reduce the ship's effective cargo space, especially for ships with high deck space utilisation; this reduces the economic value of merchant ships, such as container ships [26, 27].

It will be of great significance if a rotating cylinder can be designed that can not only assist the navigation of the ship but also save space on the ship's deck. Based on the above discussion, this article proposes a new type of Flettner rotor installation and method of use, such that the rotating cylinder and superstructure are cleverly combined and a transparent cylinder is set on the outer side of the ship's superstructure. On the basis of not affecting the original functions of the superstructure, a huge-sized Flettner rotor and a new type of rotating cylinder was created. This can increase the windreceiving area of the rotating cylinder so that the wind energy can be used to a greater extent and there is no need to install a separate cylinder on the deck. This saves installation space and it will not affect the layout of deck cargo spaces and machinery, or the loading and unloading of ships. This new type of vertical rotating cylinder uses the Magnus effect, as shown in Fig. 2. Harnessing the power of wind to generate thrust increases efficiency by reducing fuel consumption, bunker costs and harmful emissions. The new rotating cylinder can be installed on newly built ships, which will generate a large amount of thrust to assist the ship's navigation. In general, Flettner rotors can use a small proportion of ship auxiliary power to achieve rotation; its potential to save main engine fuel consumption can reach $3 \%$ to $25 \%$. It has economic value for merchant ships.

\section{THE STRUCTURE OF THE NEW ROTATING CYLINDER AND ITS INSTALLATION}

The Flettner rotor usually works in lateral winds and the amount of thrust that it generates mainly depends on wind and ship speed. For merchant ships, the beneficial effects of the actual installation and use of the Flettner rotor depends on the size of the ship, the sailing area, and the operational profile. In order to analyse and evaluate the contribution of the new of type rotating cylinder, a 100,000 ton tanker ship was selected as an example of a ship fitted with a rotating cylinder. The number of superstructure floors of the merchant ship is 6 . In order to avoid disturbing the observation of the ship's crew on the navigation deck, the highest edge of the cylinder is set up at the lower edge of the navigation deck; the lowest edge is set up at the upper edge of the superstructure on the first floor. This design does not affect the passing function of the personnel between the superstructure and the main deck. In addition, the navigation deck is circular and its diameter equal to the width of the ship, to ensure that the driver can easily watch the berthing process. Therefore, the specific structure of the new rotating cylinder is: a circular, hollow cylinder made of transparent material and enveloped in the middle part of the superstructure. It is driven by a motor to achieve rotation around the axis, and to obtain better rotor performance without affecting the original function of the superstructure. There is an endplate on the top of superstructure, as shown in Fig. 2. When the ship is sailing on the sea, the rotating cylinder is affected by lateral winds, which causes it to produce Magnus thrust. Besides this, the use of transparent materials for the rotating cylinder material can ensure sufficient light into the superstructure. There are emergency stop buttons on each floor of the superstructure; emergency stop buttons and life-saving hammers are installed on the floors near the lifeboat. The first purpose of this design is to make an emergency stop when the 
rotating cylinder is in danger, the second is to stop the rotating cylinder when the ship encounters a dangerous situation; the relevant personnel then smash the transparent materials with a life-saving hammer to escape the scene in time.

The new rotating cylinder has great advantages. On the one hand, a major feature of the cylinder is its large diameter. This structure increases the wind-receiving area of the cylinder. It can be seen from the conditions that produce the Magnus effect force that increasing the wind area of the rotating cylinder also increases the lift of the cylinder. On the other hand, due to the windward surface usually being flat to the traditional ship's superstructure, the wind friction caused by the ship's sailing process is relatively large. When a rotating cylinder is set in the ship's superstructure. The crosssection of a cylinder is a circle and its sides are approximate streamlined. Therefore, the cylinder can reduce the friction of the superstructure. The shape of the superstructure will be compared and demonstrated in Section 4.1. Last but not least, all kinds of merchant ships have superstructures and the rotating cylinder can be appropriately improved, so the new rotating cylinder is suitable for many types of merchant ships.

The more common 100,000 ton class of ship was selected in this analysis, with the oil tanker "Bei Hai Wei Wang" of COSCO SHIPPING being the typical ship specifically used; some of its parameters are shown in Tab. 1. Generally, the height of a single deck of a merchant superstructure is $3.05 \mathrm{~m}$, the height of the cylinder $(\mathrm{H})$ is equal to about 4 decks in the middle of the superstructure $(\mathrm{H}=12.5 \mathrm{~m})$. In order to use the space as effectively as possible and to increase the area of the rotating cylinder, its diameter (D) should be as close to the width of the ship as possible; take $\mathrm{D}=40 \mathrm{~m}$. Moreover, the new rotating cylinder can ensure the normal basic functions of the ship's superstructure; the cylinder here is a cylinder with a diameter of $40 \mathrm{~m}$ and a height of $12.5 \mathrm{~m}$. The endplate diameter is $42 \mathrm{~m}$.

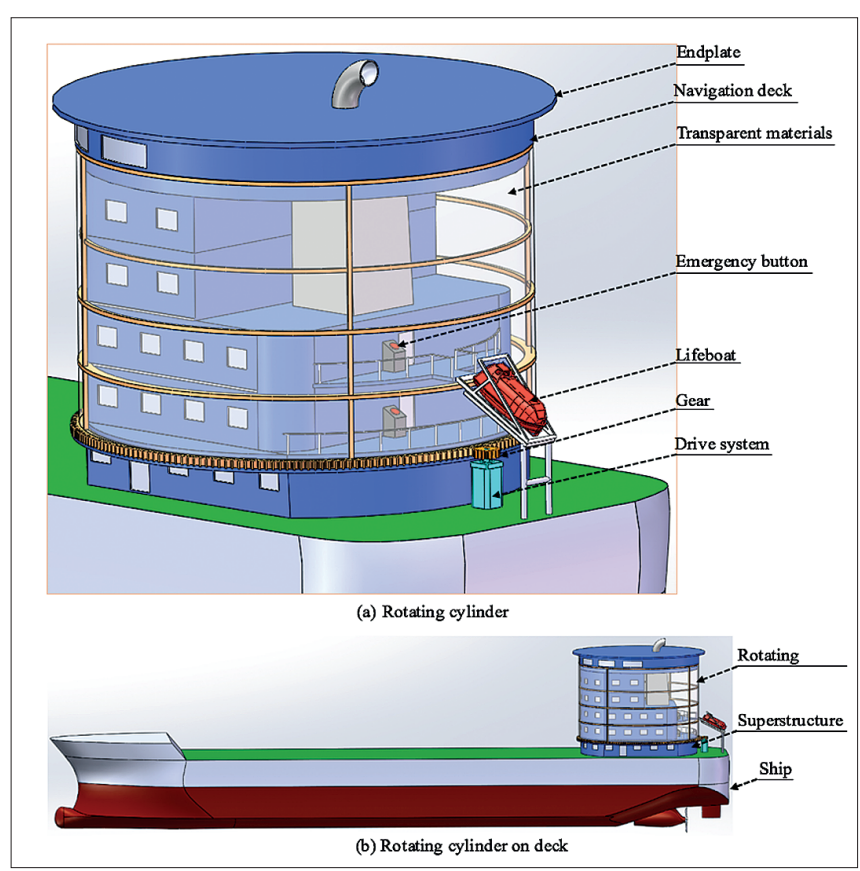

Fig. 2.The new rotating cylinder and its installation position on the ship
Tab. 1. Parameters of "Bei Hai Wei Wang"

\begin{tabular}{|c|c|c|c|}
\hline Parameters & Value & Parameters & Value \\
\hline Type & Aframax & Draft (m) & 11.90 \\
\hline Length overall (m) & 243.00 & Deadweight (ton) & 104404 \\
\hline Breadth moulded (m) & 42.00 & Main engine power (kW) & 15260 \\
\hline Depth (m) & 20.63 & Maximum speed (knots) & 15 \\
\hline
\end{tabular}

\section{PHYSICAL AND NUMERICAL MODELS}

\section{PHYSICAL COMPUTING MODELS}

When the ship is subjected to the effects of environmental wind $\left(V_{e n}\right)$, the ship will be subjected to the Magnus effect force due to the existence of the rotating cylinder. If a sensor is installed to monitor the wind in real time, the starting, stopping and steering of the rotating cylinder can be adjusted in time with the change of wind direction, so as to ensure that the Magnus force on the cylinder is maximised along the ship's direction of travel. In order to explore the potential of the new rotating cylinder as a ship booster, it is important to consider that the wind acting on the cylinder is a vector sum of the environmental wind and the ship speed. According to Eq. 1, the apparent wind speed in the vicinity of the cylinder can be calculated as $V_{a}$, in Fig. 3(a). In the following simulation, both the lateral wind perpendicular to the ship and the ship's speed are considered; the ship's speed is fixed at $5 \mathrm{~m} / \mathrm{s}$ (about 10 knots).

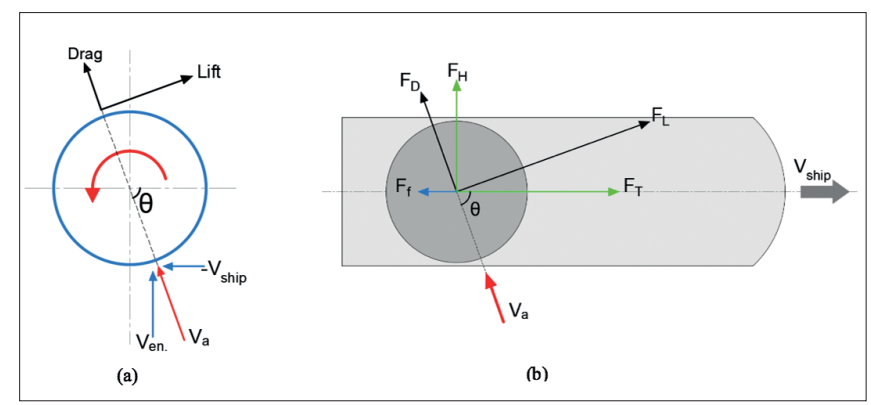

Fig. 3. Diagrams of apparent wind (a) and ship force (b)

The thrust $\left(C_{T}\right)$ and heel coefficients $\left(C_{H}\right)$ vary with the size and direction of the angular velocity of the cylinder and the apparent wind speed during the ship voyage. They are transformed by the lift coefficient $\left(C_{L}\right)$, the drag coefficient $\left(C_{D}\right)$ and the angle $\theta$ between the apparent wind speed and heading, as realised in Fig. 3. The equations Eq. (2) and (3) for calculating $C_{T}$ and $C_{H}$ are given [9].

$$
\begin{gathered}
V_{a}=V_{\text {en. }}-V_{\text {ship }} \\
C_{T}=C_{L} * \sin ^{\theta}-C_{D} * \cos ^{\theta} \\
C_{H}=C_{L} * \cos ^{\theta}+C_{D} * \sin ^{\theta}
\end{gathered}
$$

In the ship, the thrust force $F_{T}$ and side force from the heel $F_{H}$ are calculated based on the thrust coefficient $C_{T}$, heel 
coefficient $C_{H}$, air density $\rho$, apparent wind speed $V_{a}$, and the sail area $A$ according to equations (4) and (5). The diagram of ship forces is given in Fig. 3(b).

$$
\begin{aligned}
& F_{T}=0.5 * \rho * A * V_{a}^{2} * C_{T} \\
& F_{H}=0.5 * \rho * A * V_{a}^{2} * C_{H}
\end{aligned}
$$

The power consumed by the motor rotating the cylinder and the lift, drag acting on the cylinder together determine the power value that can be generated by the rotating cylinder. The thrust obtained from the cylinder is calculated as a vector and projection of the lift and drag along the ship's course. The amount of power generated by the thrust and the power consumed by the motor are calculated, and they are given by the equations (6) and (7), where $C_{M}$ is the Moment coefficient [17].

$$
\begin{gathered}
P_{T}=T * V_{\text {ship }} \\
P_{\text {motor }}=0.5 * \rho * A * V_{a}^{3} * C_{M} * \alpha
\end{gathered}
$$

The effective power $P_{e f}$ is calculated as the difference between the power delivered by the rotating cylinder and the power that is consumed by the motor to rotate it.

$$
P_{\text {ef. }}=P_{T}-P_{\text {motor }}
$$

\section{NUMERICAL MODELS}

The purpose of the modelling was to simulate the lift, drag, thrust coefficient and other data of the rotating cylinder installed onto the ship's superstructure. This experiment used the CFD software 'Fluent' to carry out simulation calculations. The three-dimensional computational domain containing the rotating cylinder was established to obtain more accurate results. The SIMPLE algorithm was used to solve the N-S control equations and the two-order upstream scheme was chosen to ensure accuracy. The turbulence model chosen was the Realizable k- $\varepsilon$ model [28-30]. The RANS equation was used as the basic equation for solving the computational domain around the rotating cylinder, which included the continuity Eq. (9) and the momentum Eq. (10). The simulations were performed in an unsteady way.

$$
\begin{gathered}
\nabla \cdot U=0 \\
\rho \bar{u}_{j} \frac{\partial \bar{u}_{i}}{\partial x_{j}}=\rho \overline{f_{i}}+\frac{\partial}{\partial x_{j}}\left[-\bar{p} \delta_{i j}+\right. \\
\left.+\mu\left(\frac{\partial \bar{u}_{i}}{\partial x_{j}}+\frac{\partial \bar{u}_{i}}{\partial x_{i}}\right)-\rho \overline{u_{I}^{\prime} u_{J}^{\prime}}\right]
\end{gathered}
$$

where $\rho$ is the density of fluid; $U$ is the relative velocity; $\mu$ is liquid viscousness; $\bar{p}$ is static pressure; $\delta_{i j}$ is Kronecker delta; $\overline{f_{i}}$ is the mass force term; $-\rho \overline{u_{I} u_{J}}$ is apparent stress owing to the fluctuating velocity field, generally referred to as the Reynolds stress.

\section{COMPUTATIONAL DOMAIN AND BOUNDARY CONDITIONS}

As shown in Fig. 4(a), the entire computational domain is shaped as a rectangle with a length of $22.5 \mathrm{D}$, a width of $17.5 \mathrm{D}$, and a height of $12.5 \mathrm{D}$, where $\mathrm{D}$ is the diameter of the rotating cylinder, and the Cartesian coordinate system origin is centred at the bottom of the cylinder. The whole computational domain is arranged by coupling structured and unstructured grids, specifically tetrahedral grids near the ship; the grids around the rotating cylinder are encrypted; and layer boundary grids on the surface of the rotating cylinder are established $[31,32]$. The other regions use structured grids, as in Fig. 4(b). Furthermore, the grid set up allowed a non-dimensional wall distance $(y+)$ value approximately equal to 1.0; the Max-Skewness is 0.84 and the blocking ratio is about $1.2 \%$.

The computational domain is shown in Fig. 4(a). The right side and the front side of the ship are the inlet boundary, which adopts the velocity inlet boundary condition. The environmental wind direction is positive along the $y$-axis and the ship's sailing direction is positive along the $\mathrm{x}$-axis; the wind speed condition is the apparent wind speed $V_{a}$ and it is referenced to the above-mentioned apparent wind in Fig. 3(a). The outlet boundary adopts the pressure outlet boundary condition and the value is one atmospheric pressure. The wall is used at the top and bottom of the computational domain. The $1.5 \mathrm{D}$ range near the cylinder surface is the rotating area (circle), as shown in Fig. 4(b). The cylinder surface is a nonslip wall with a certain roughness and the cylindrical circle area is turned in a counter-clockwise direction.

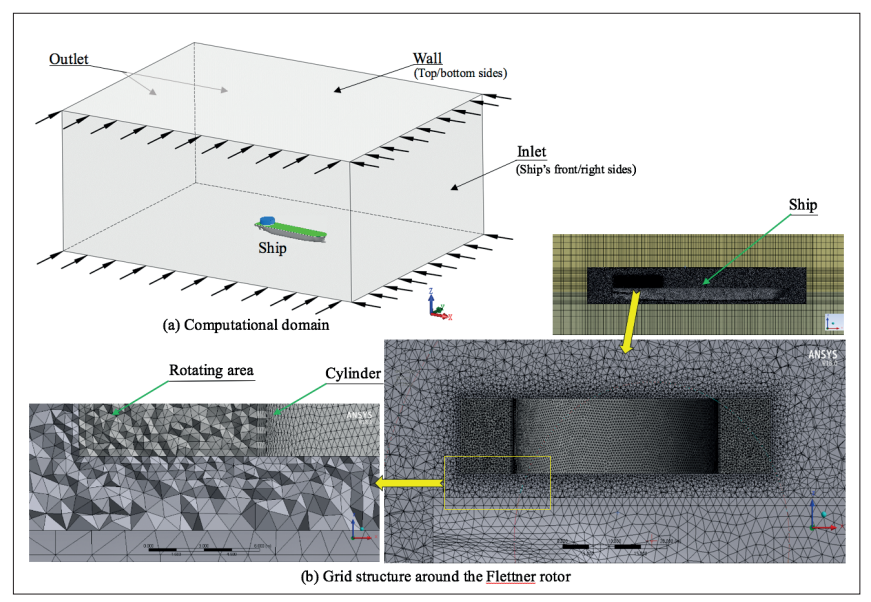

Fig. 4. Computational domain and boundary conditions

The $1.5 \mathrm{D}$ diameter rotating area is used to simulate the domain generated by the rotation of the cylinder, which is especially suitable for rotational movements [33]. It should be noted that the time step of the simulation is a function of 
the angular velocity $(\omega)$. For the convergence of the numerical scheme, according to experience, there is a limitation on the maximum cell-based Courant-Friedrichs-Lewy (CFL) number in a time step [11]. Therefore, a larger angular velocity should correspond to a smaller value of time step.

\section{GRID INDEPENDENCE ANALYSIS AND COMPARISON DATA VALIDATION}

The grid independence study is performed by using four different grid densities with approximately 3,500,000, 4,000,000, 4,500,000 and 6,000,000 elements. The pressure coefficient $C_{p}$ is used for comparing different grids when verifying the numerical method. The other conditions for this comparative validation were: 5 -level wind, spin ratio $\alpha$ is 2 , and $\operatorname{Re}$ is $3.08^{\star} 10^{7}$. The $C_{p}$ data curves, corresponding to the four grids, are shown in Fig. 5 and Table 2 shows the result of grid independency validation. It is concluded from the comparative analysis that the grid reaches 4,500,000 elements and further increases in grid density do not significantly affect the results. The error of the $C_{p}$ is less than $0.4 \%$ when compared with the case of 6,000,000 elements. Therefore, the calculation of the efficiency and accuracy are taken into account and the numerical simulation is based on a grid of about 4,500,000 elements [34].

Tab. 2. Results for grid independency validation

\begin{tabular}{|c|c|c|c|c|}
\hline Description & Scale & $\begin{array}{c}\text { Element } \\
\text { number }\end{array}$ & $\begin{array}{c}\text { Average- } C_{p} \\
(35-40 \mathrm{~s})\end{array}$ & $\begin{array}{c}\text { Error of } \\
\text { average- } C_{p}\end{array}$ \\
\hline \multirow{3}{*}{$\begin{array}{c}\text { Grid } \\
\text { independence } \\
\text { validation }\end{array}$} & Coarse & $3,500,000$ & -0.747 & $1.1 \%$ \\
\cline { 2 - 5 } & Medium & $4,000,000$ & -0.730 & $1.2 \%$ \\
\cline { 2 - 5 } & Fine & $4,500,000$ & -0.736 & $0.4 \%$ \\
\cline { 2 - 5 } & Very fine & $6,000,000$ & -0.739 & 0 \\
\hline
\end{tabular}

In addition, since the objective conditions limited the experimental validation of the device, we simulated the example for the experiments performed by Bordogna et al. using the CFD grid processing method and simulation procedure in the paper. The specific experimental conditions of the cylinder were $\mathrm{H}=3.73 \mathrm{~m}, \mathrm{D}=1 \mathrm{~m}$ and $\mathrm{Re}=1.0^{\star} 10^{6}[10]$. The results of the numerical simulation should be compared with experimental data. The simulation results are shown in Fig. 5(b) "Experimental data vs CFD simulation results" and it can be seen that the two results are generally consistent. Therefore, similarly, our simulations have some reliable accuracy in the study.

\section{ANALYSIS OF THE RESULTS}

To verify the characteristics and boosting effect of the new rotating cylinder, the characteristics of the rotating cylinder and the traditional superstructure (middle section) will be compared in Section Comparison of different types of superstructure. In Section Discussion on spin ratios and wind levels, the parameters of cylinder lift coefficient, drag coefficient, and thrust coefficient corresponding to different spin ratios under wind speed conditions of 5, 6, 7 and 8 levels, are investigated. In Section Energy contribution to ship navigation, the contribution of the rotating cylinder to the ship's boosting is studied. In order to verify the influence of the variation of Reynolds number on the cylinder, a brief discussion is made in Section The influence of Reynolds number on the performance of the new rotating cylinder.

In order to obtain more realistic simulation results, the following apparent wind speed is the result of considering the combined effects of ship speed and environmental wind speed (see Fig. 3(a)). The ship speed is approximately $10 \mathrm{knots}$ and environmental wind speed regulations are shown in Table 3.

Tab. 3. Environmental wind speed

\begin{tabular}{cllll}
\hline Wind level & 5 & 6 & 7 & 8 \\
\hline Environmental wind speed $(\mathrm{m} / \mathrm{s})$ & 10 & 12 & 15 & 20 \\
\hline
\end{tabular}

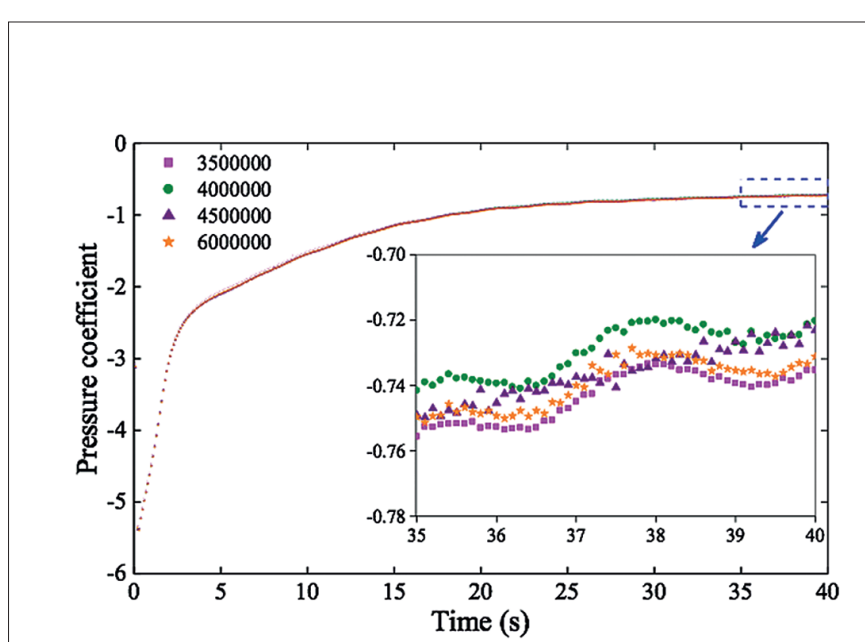

(a) Data curves of $C_{p}$

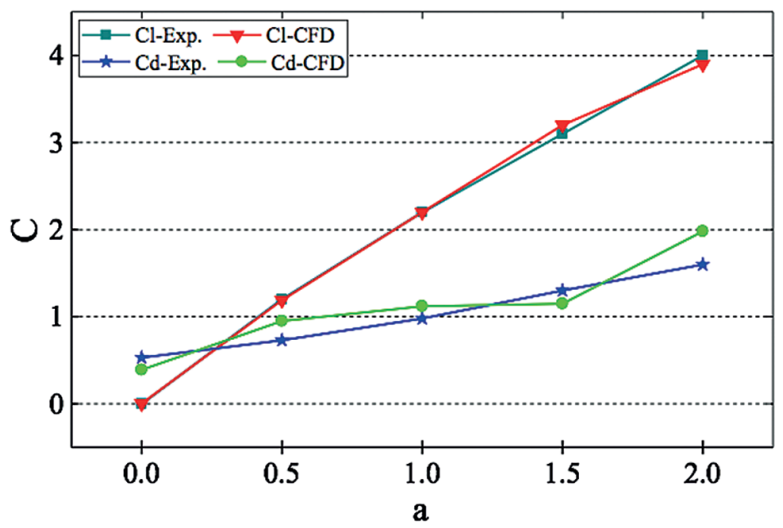

(b) Experimental data vs CFD simulation results 


\section{COMPARISON OF DIFFERENT TYPES OF SUPERSTRUCTURE}

\section{COEFFICIENTS OF FORCE FOR ROTATING CYLINDER AND TRADITIONAL SUPERSTRUCTURE}

The traditional superstructure consists of 4 to 6 floors; the middle 4 floors of the superstructure can be approximated into a rectangular shape, without considering the Navigation deck and the first-floor superstructure. In order to compare the effects of the new cylinder superstructure with the traditional superstructure on the ship's navigation, the friction coefficients $\left(C_{f}\right)$ and heel coefficients $\left(C_{H}\right)$ generated by the different types of superstructure are investigated under 5-level wind conditions. The volumetric parameters of the three superstructure types (traditional type, cylinder type and rotating cylinder type) are given in Table 4, and the three volumes are equal. The superstructure of the new rotating cylinder type is proposed in this paper, it is modified or added to the middle 4 floors of the superstructure on the basis of not affecting the function of the ship's superstructure.

The friction coefficient $\left(C_{f}\right)$ graph and the average friction $\left(F_{f}\right)$ bar graph for three types of superstructure are shown in Fig. 6(a). As can be seen, the friction coefficient of the traditional and cylinder superstructure is positive in $20 \mathrm{~s}$, i.e. the friction generated by the superstructure of the ship's navigation process has always existed. The traditional type produces an average friction of $94,877.73 \mathrm{~N}$; the cylinder's average friction is $4,833.31 \mathrm{~N}$. Moreover, the friction coefficient of the traditional type is greater than the friction coefficient of the cylinder type. So, cylinder type superstructure has a certain effect on reducing wind friction compared to the traditional type. It is worth noting that the friction coefficient at $20 \mathrm{~s}$ is negative about the rotating cylinder type; its average friction of $-151,520.34 \mathrm{~N}$ indicates that the superstructure of rotating cylinder type produced a forward thrust.
Tab. 4. Three types of superstructure

\begin{tabular}{|c|c|c|c|}
\hline Type & Size $(\mathrm{m})$ & $\alpha$ & \multirow{2}{*}{ Volume $\left(\mathrm{m}^{3}\right)$} \\
\hline Traditional & $35^{\star} 35^{\star} 12.5$ & 0 & \multirow{2}{*}{15,700} \\
\cline { 1 - 3 } Cylinder & $40^{\star} 12.5$ & 0 & \\
\cline { 1 - 3 } Rotating cylinder & $40^{\star} 12.5$ & 2.0 & \\
\hline
\end{tabular}

In Fig. 6(b), the heel coefficients $\left(C_{H}\right)$ and average heel forces $\left(F_{H}\right)$ for the three types of superstructures are shown, respectively. Three types of superstructure heel coefficient are positive, the cylinder type superstructure produces the smallest heel coefficient and the heel coefficient of the rotating cylinder type is the largest. By observing the three types of heel force it can be seen that the average lateral force of the traditional, cylinder, and rotating cylinder type superstructures are 55,772.91 N, 16,060.64 $\mathrm{N}$ and $79,515.39 \mathrm{~N}$, respectively. Due to the additional friction generated by the rotating cylinder superstructure, as a result of Magnus forces acting on the rotating cylinder of $\alpha=2.0$, the heel force for a rotating cylinder of the same size is greater than for a cylinder of $\alpha=0$.

\section{PRESSURE DISTRIBUTION AROUND THE SUPERSTRUCTURES}

The three types of pressure distribution around the superstructures are given using the CFD-post processing function. Fig. 7 shows the wind pressure area around the superstructures on the mid-plane (in the middle of the cylinder in the $\mathrm{z}$-axis).

It can be seen that the high-pressure area in all three figures is mainly located below the superstructures (because the $y$-axis direction is the environmental wind inlet, which has a value of $10 \mathrm{~m} / \mathrm{s}$ ). The maximum wind pressure in the high-pressure area of the traditional type superstructure can be seen as $95 \mathrm{~Pa}$ in Fig. 7(a). In Fig. 7(b), the maximum wind pressure around the cylinder type superstructure is $92 \mathrm{~Pa}$ and its high-pressure area is smaller. Fig. 7(c) shows

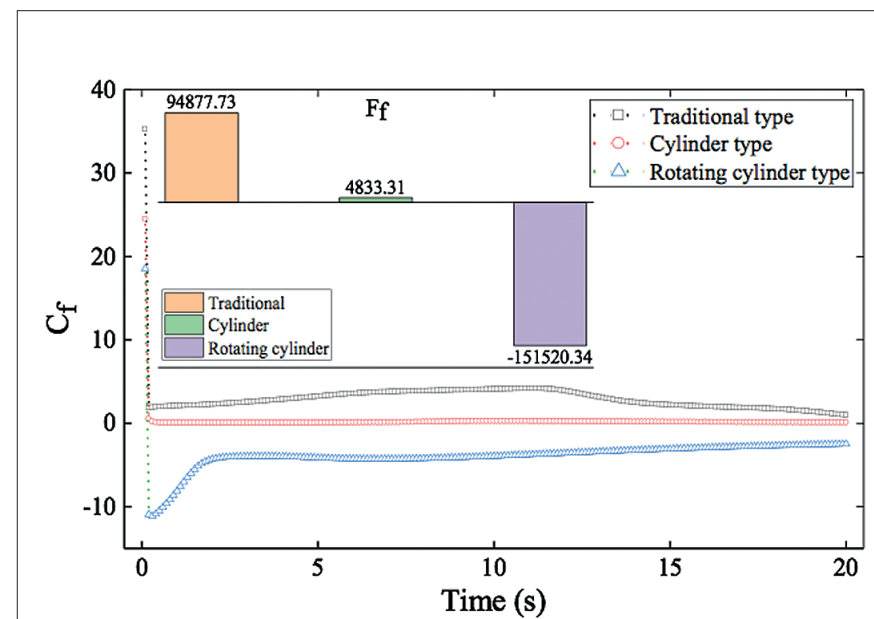

(a)

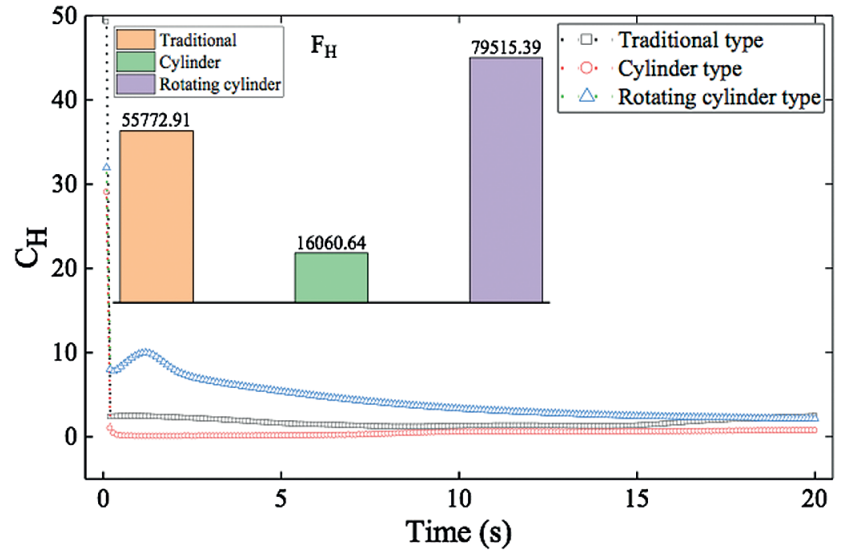

(b)

Fig. 6. Forces and force coefficients of the three types of superstructure 


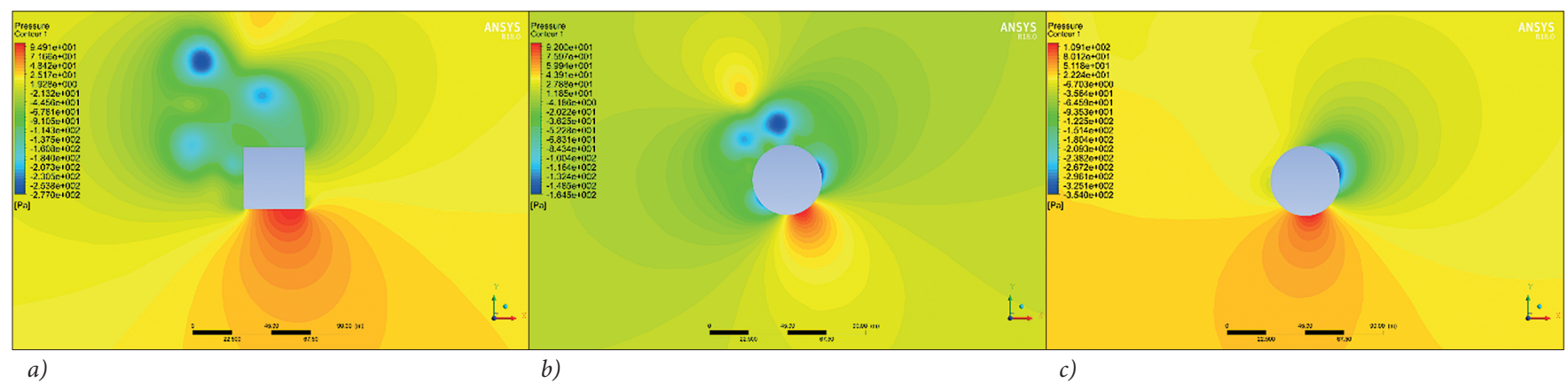

Fig. 7. Wind pressure area around the three kinds of superstructures on the mid-plane

the wind pressure around the rotating cylinder, which is also the main object of the simulation. The comparison with the other two graphs shows that the pressure of the rotating cylinder type and cylinder type superstructure are clearly different; the right side of the rotating cylinder (the direction of the ship's navigation) is a low pressure area, so, the whole rotating cylinder will be subjected to pressure along the $\mathrm{x}$-direction. Due to the rotation of the cylinder, there is the Magnus effect around it, which creates a beneficial pressure differential. The ship is fitted with a rotating cylinder to take advantage of the lateral wind, which helps the ship move forward.

\section{DISCUSSION ON SPIN RATIOS AND WIND LEVELS}

\section{THE EFFECTS OF DIFFERENT SPIN RATIOS ON THE LIFT AND DRAG COEFFICIENT FOR THE ROTATING CYLINDER}

According to the relevant studies $[11,16]$, the environmental wind speed and the ship speed, as well as the angular velocity of the cylinder, have a significant influence on the lift coefficient of the rotating cylinder. The variation of the spin ratio $(\alpha)$

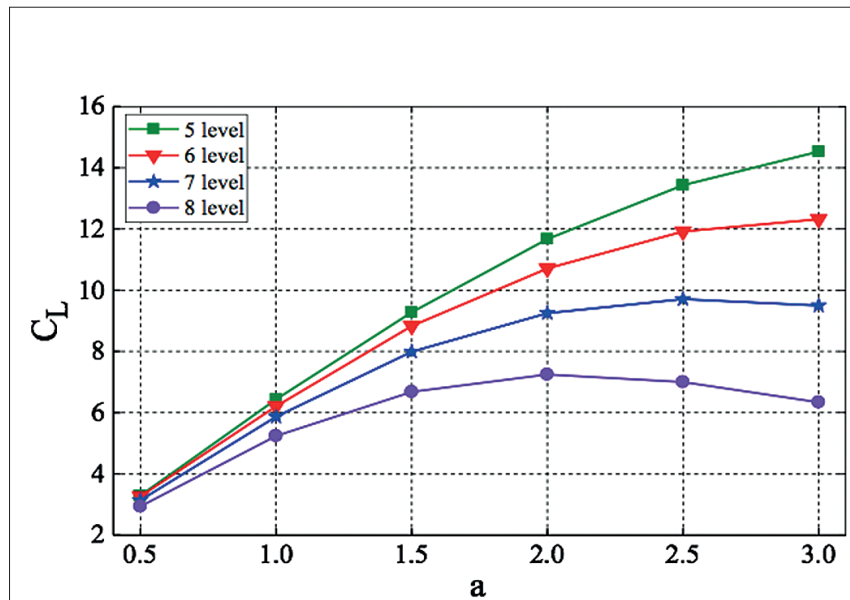

(a)

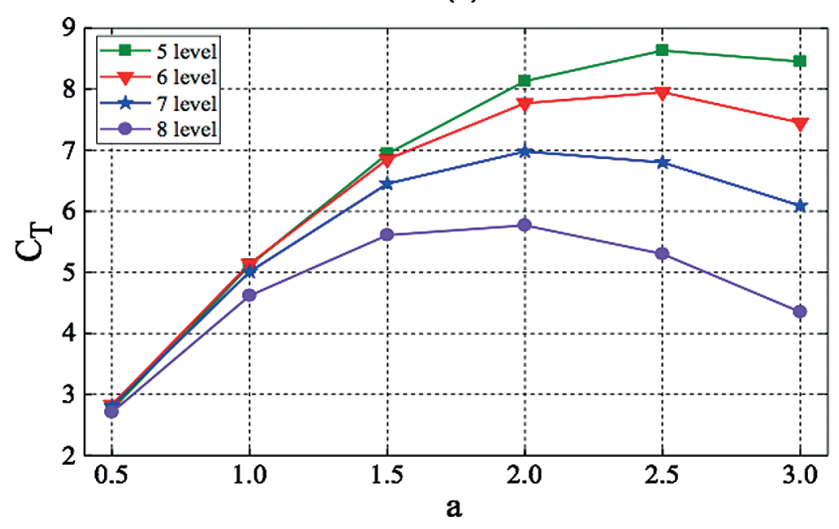

(c)

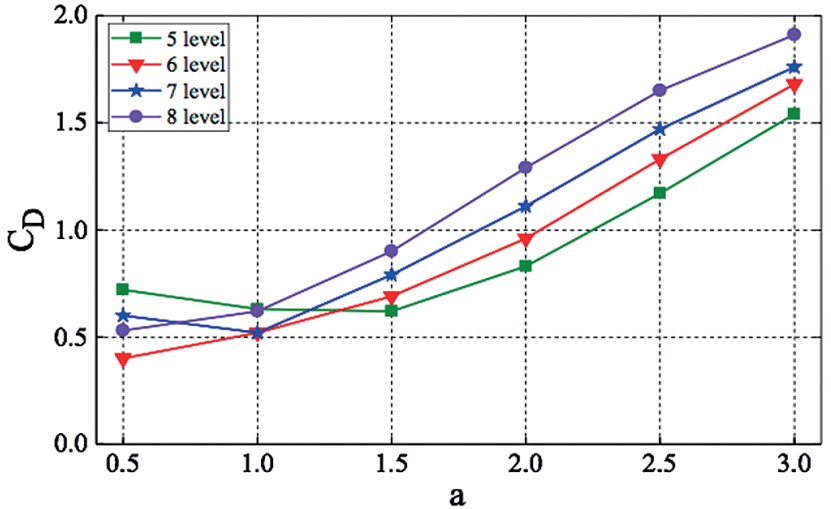

(b)

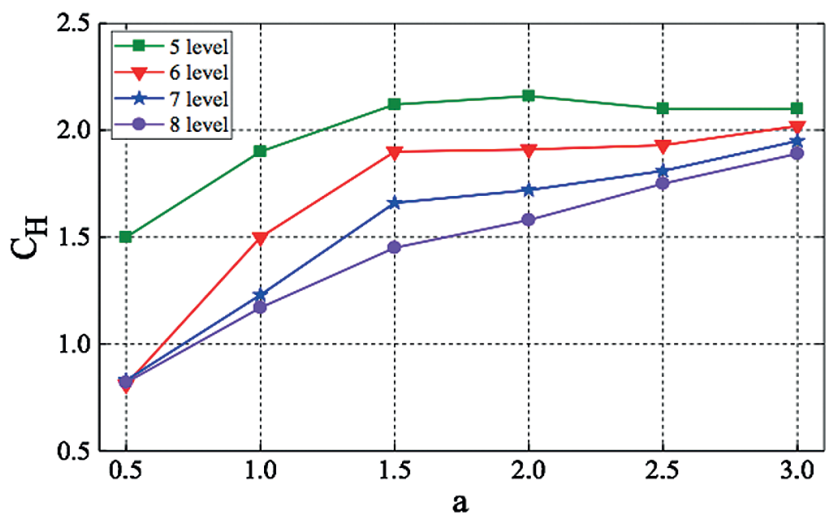

(d)

Fig. 8. The force coefficient of the rotating cylinder 
affects the contribution of the rotating cylinder to navigation. In order to study the contribution of the rotating cylinder with different spin ratios, the changing effects of the spin ratio on the same rotating cylinder at different wind levels will be discussed separately. Specifically, the rotating cylinder lift coefficient $\left(C_{L}\right)$, drag coefficient $\left(C_{D}\right)$, thrust coefficient $\left(C_{T}\right)$, and heel coefficient $\left(C_{H}\right)$ is given to analysis and discussion. The force coefficient of the rotating cylinder is shown in Fig. 8.

Fig. 8 is the point line graph of the lift coefficient, drag coefficient, thrust coefficient and heel coefficient for a rotating cylinder in 5, 6, 7, and 8 level wind conditions. From the figure, it can be seen that the spin ratio has a significant impact on the force coefficient of the cylinder. Fig. 8(a) is the rotating cylinder lift coefficient graph. Wind levels of 5 and 6 correspond to the lift coefficient gradually increasing with an increase in spin ratio and the maximum lift coefficient can reach 14.53 . Wind levels of 7 and 8 correspond to the lift coefficient and inflection points can be seen, wind level 7 corresponding to the lift coefficient's maximum value of 9.71 , which appears when the spin ratio is 2.5 . Level 8 corresponds to the maximum value of lift coefficient appearing at a spin ratio of 2.0.

Fig. 8(b) shows the drag coefficient of the rotating cylinder, the curves corresponding to wind levels 6, 7 and 8, showing an overall upward trend as the spin ratio increases. In the case of level 5 wind, the drag coefficient appears to be the smallest value when the spin ratio is 1.5 , after which the coefficient becomes larger. By observing the directional trend of the drag coefficient curve, it can be assumed that, due to the Magnus effect, the drag coefficient becomes larger and larger as the spin ratio continues to increase. This trend of increasing drag coefficient is consistent with the results of Liu et al. [25].

In Fig. 8(c), it can be seen that the thrust coefficient first increases and then decreases with the increase in spin ratio for the rotating cylinder. The four kinds of wind inflection point are different. That is to say, the thrust coefficient of a cylinder has the best value with a change of spin ratio. This means that the thrust coefficient becomes smaller with an increase in environmental wind speed, but it does not mean that the cylindrical thrust contribution to the ship becomes smaller.

Fig. 8(d) shows the curves of heel coefficient for the rotating cylinder. It can be seen that the heel coefficients increase as the spin ratio increases, but their curve steepness becomes progressively smaller. At the same spin ratio, the heel coefficient of the rotating cylinder becomes smaller as the apparent wind speed increases. In addition, the maximum value of the thrust coefficient in Fig. 8(c) is 8.63 under the 5-level wind condition. The maximum value of heel coefficient in Fig. 8(d) is 2.16, which shows that the thrust contribution to the ship brought by the installation of the rotating cylinder is much larger than the heel force generated by it. This also shows that the new type of rotating cylinder is very beneficial to the ship's sailing.

\section{PRESSURE AROUND THE ROTATING CYLINDER AT DIFFERENT SPIN RATIOS}

In order to better analyse the pressure values around the cylinder for different spin ratios, the pressure graphs are given spin ratios of $0.5,1.0,1.5,2.0,2.5$ and 3.0 in a level 6 wind, respectively. As shown in Fig. 9, wind pressure area and contours are plotted around the cylinder on the mid-plane for different spin ratios. This Reynolds number is $3.59^{\star} 10^{7}$.

It can be seen from the figure that a low pressure area appears on the right side of the cylinder; the presence of this pressure difference causes a thrust along the ship's sailing direction. Fig. 9(a) shows the pressure distribution for the spin ratio of 0.5 , compared with the other images, the pressure difference around the cylinder along the $\mathrm{x}$-axis direction in Fig 9(a) is the least obvious; it can be seen from the pressure contour in the figure that its maximum pressure difference is $515.7 \mathrm{~Pa}$. In addition, as the spin ratio increases, the pressure difference around the cylinder along the $\mathrm{x}$-axis direction becomes larger. At the spin ratio equal to 2.0, the maximum difference of the contour is reached at $900.3 \mathrm{~Pa}$. This indicates that there is an optimal value of the spin ratio
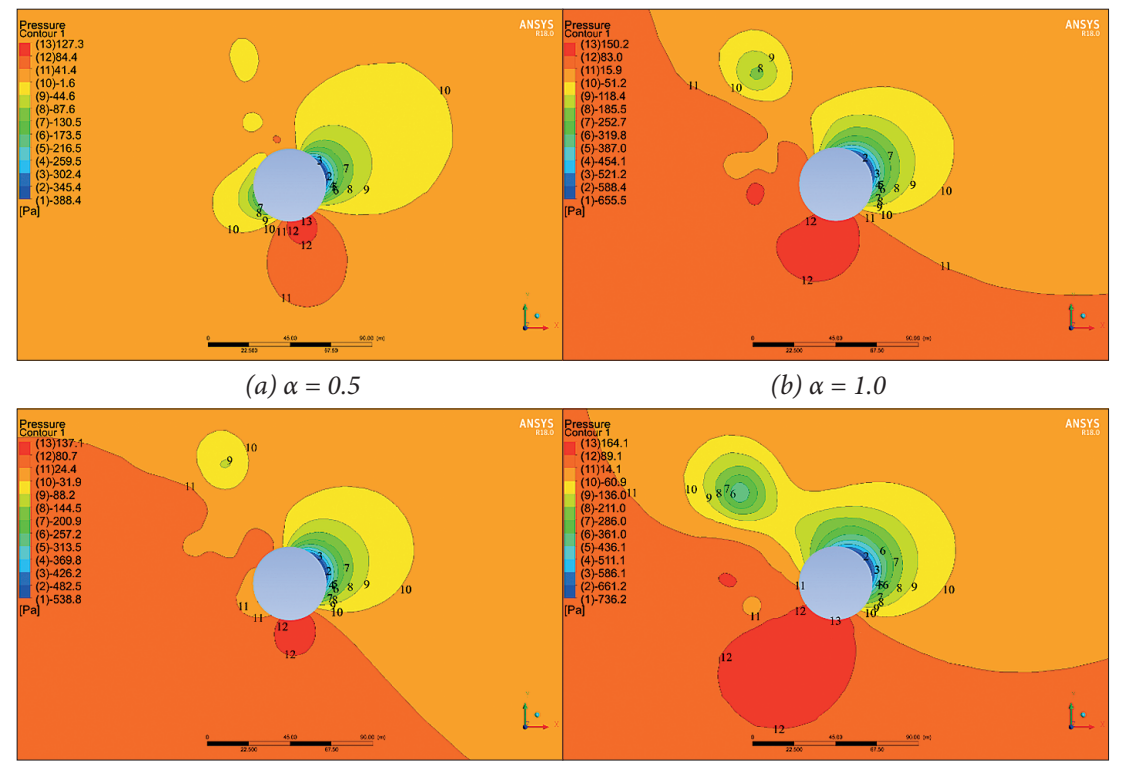

(c) $\alpha=1.5$

(d) $\alpha=2.0$

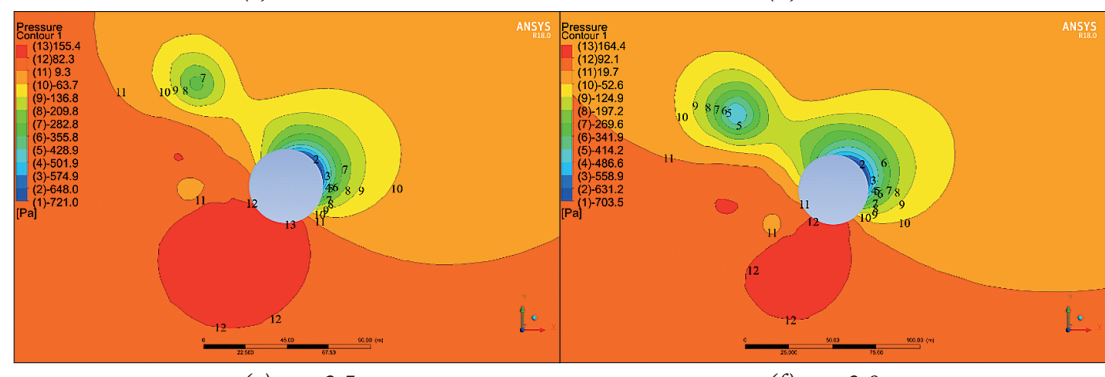

(e) $\alpha=2.5$

(f) $\alpha=3.0$

Fig. 9. Wing pressure area and contours plotted around the cylinder on the mid-plane for different spin ratios 
of the new rotating cylinder of about 2.0. It can also be proved that the spin ratio is one of the main factors influencing the Magnus effect of the cylinder, by comparing the pressure. So, it is necessary to change the angular velocity of the rotating cylinder in real time according to the change of the environmental wind.

\section{THRUST CONTRIBUTION OF ROTATING CYLINDER}

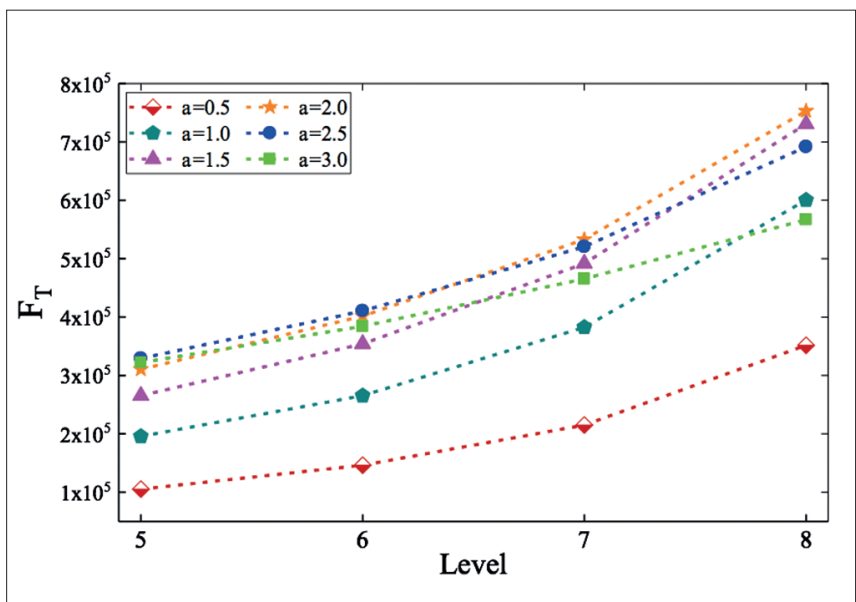

Fig. 10. Thrust of rotating cylinder

Fig. 10 shows the thrust curves of the rotating cylinders, corresponding to different wind levels for the six kinds of spin ratio conditions. As can be seen from the figure, the greater the environmental wind speed, the greater the thrust contribution generated by the cylinder in the same spin ratio. When the spin ratio is 0.5 , the thrust is the smallest. In the four kinds of wind levels, the spin ratio of 2.5 corresponding to the cylinder thrust has been greater than the spin ratio of 3.0. The thrust corresponding to $\alpha=1.5$ and 2.0 shows a steeper rise when the wind level increases. Finally, the two thrusts reach their maximum value of more than $750,000 \mathrm{~N}$ under the wind level 8 conditions. At the same time, this set of curves shows that it is not the larger spin ratio that corresponds to the rotating cylinder's thrust contribution. On the contrary, the rotating cylinder shows a better advantage when $\alpha=2.0$.

\section{ENERGY CONTRIBUTION TO SHIP NAVIGATION}

The power consumed by an electric motor and the lift and thrust acting on the cylinder determine the power of the main engine that a rotating cylinder can replace. It is necessary to study the actual energy contribution of the rotating cylinder to the ship. Due to the existence of the Magnus effect, the rotating cylinder generates positive thrust that provides the ship's navigation. The thrust power $\left(P_{T}\right)$ and effective power $\left(P_{e f}\right)$ of the rotating cylinder corresponding to different spin ratios are analysed in Fig. 11.

As shown in Fig. 11, the four bar graphs indicate the thrust power and effective power corresponding to the wind conditions of levels 5, 6, 7 and 8, respectively. On the whole, the thrust power shows a tendency to increase and then decrease as the spin ratio increases; the maximum thrust power for wind levels of 5 and 6 are 1,649,351 W and $2,057,131 \mathrm{~W}$ respectively at the spin ratio of 2.5 ; the maximum thrust power for wind levels of 7 and 8 are 2,669,711 W and $3,763,193 \mathrm{~W}$ at the spin ratio of 2.0 .

More valuable than the thrust power of information is the effective power of the rotating cylinder, since it considers the removal of the motor power $\left(P_{\text {moto }}\right)$. In combination with the analysis in Fig. 11 and Table 5, it can be seen in Fig. 11(a) that the maximum effective power value is $1,125,122 \mathrm{~W}$ at a spin ratio of 1.5. In Fig. 11(b), the maximum effective power value is $1,436,422 \mathrm{~W}$ at a spin ratio of 1.5 under level 6 wind. Similarly, the maximum effective power in Fig. 11(c) is $1,827,413$ W. However, as can be seen in Fig. 11(d), the maximum effective power corresponding to level 8 occurs at a spin ratio of 1.0 , which is $2,248,611 \mathrm{~W}$. A comparison of the maximum effective power in the four cases shows that the maximum effective power of the rotating cylinder becomes larger as the environmental wind speed increases. Table 5 shows that, when the maximum effective power occurs, the effective power of the rotating cylinder can reach 75 to $85 \%$ of its thrust power, which also shows that the contribution of the rotating cylinder to the ship's propulsion is much larger than the energy consumed by its own rotation.

Tab. 5. Value comparison of maximum power

\begin{tabular}{|c|c|c|c|c|}
\hline $\begin{array}{c}\text { Wind } \\
\text { level }\end{array}$ & $\begin{array}{c}\text { Maximum } \\
\text { effective } \\
\text { power (W) }\end{array}$ & Spin ratio & $\begin{array}{c}\text { Thrust } \\
\text { power (W) }\end{array}$ & $\begin{array}{c}\text { Effective } \\
\text { power/ } \\
\text { Thrust power }\end{array}$ \\
\hline 5 & $1,125,122$ & 1.5 & $1,331,002$ & $85 \%$ \\
\hline 6 & $1,436,422$ & 1.5 & $1,775,421$ & $81 \%$ \\
\hline 7 & $1,827,413$ & 1.5 & $2,464,121$ & $74 \%$ \\
\hline 8 & $2,248,611$ & 1.0 & $3,006,123$ & $75 \%$ \\
\hline
\end{tabular}

\section{THE INFLUENCE OF REYNOLDS NUMBER ON THE PERFORMANCE OF THE NEW ROTATING CYLINDER}

The experimental study by Bordogna et al. showed that the Reynolds number is one of the factors affecting the lift coefficient and drag coefficient of a rotating cylinder $[10,15]$. We conducted a simple comparative analysis of the lift coefficient, drag coefficient and thrust value of the new rotating cylinder under several different Reynolds number conditions. The specific simulation still refers to the ship's sailing speed of $5 \mathrm{~m} / \mathrm{s}$ and the air kinematic viscosity $v=1.45^{\star} 10-5 \mathrm{~Pa} / \mathrm{s}$. Fig. 12 shows the lift coefficient and drag coefficient of the rotating cylinder when the spin ratio is 1.5 and 2.5 . 


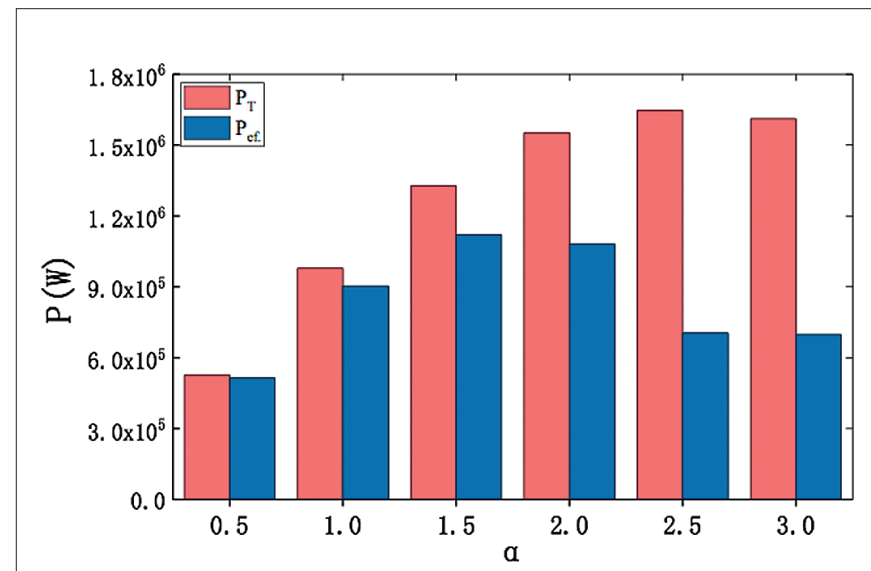

(a) 5 level

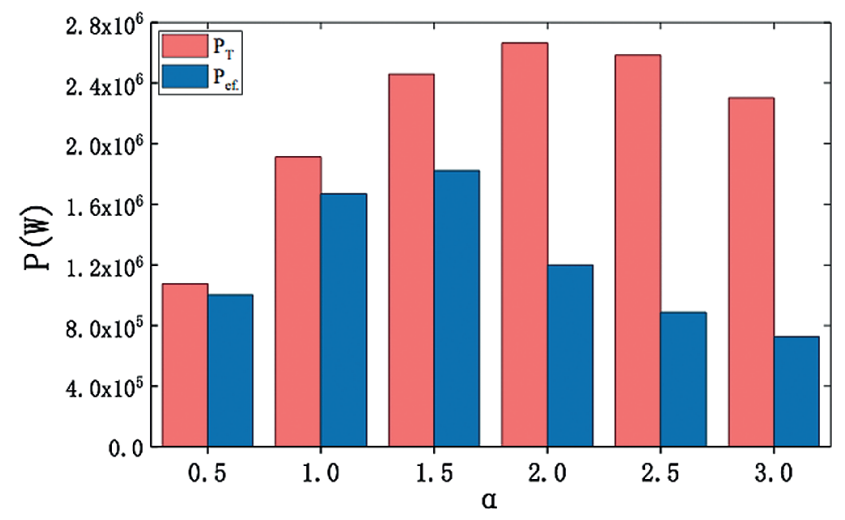

(c) 7 level

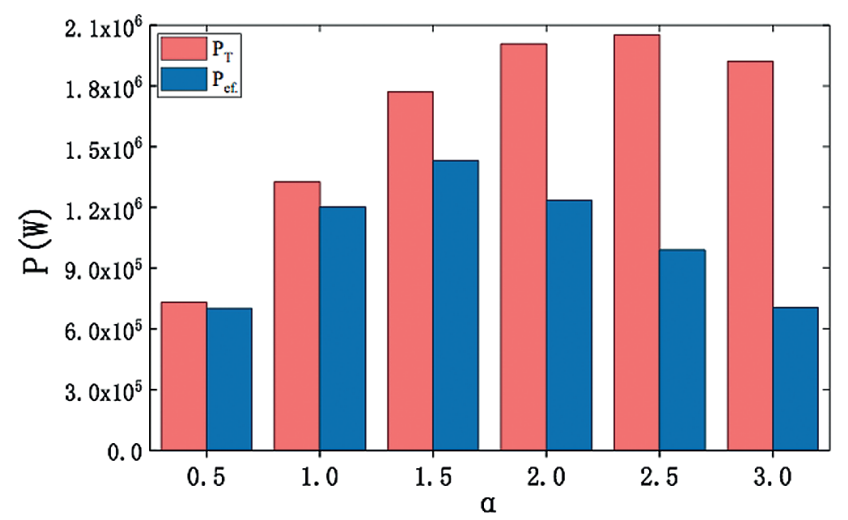

(b) 6 level

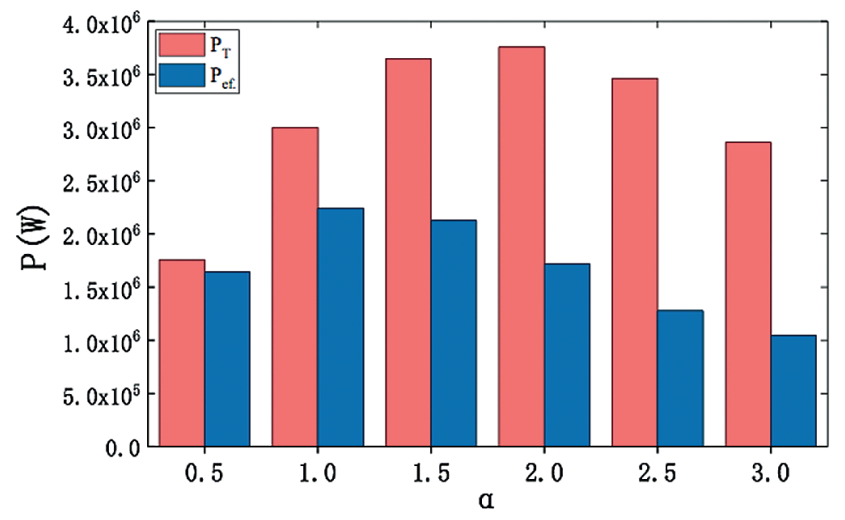

(d) 8 level

Fig. 11. The thrust power and effective power of the rotating cylinder

Fig. 12 shows the parameter comparison graph of the rotating cylinder under different Reynolds number conditions, in which the bar graph shows the lift coefficient and drag coefficient; the point line graph is its thrust. The spin ratios in Figs. 12(a) and (b) are 1.5 and 2.5, respectively. It can be seen from the figure that, as the Reynolds number increases, the lift coefficient of the rotating cylinder gradually decreases, and the drag coefficient gradually increases; the thrust curve of the ship shows an upward trend. When the spin ratio is 1.5 , the maximum thrust of the rotating cylinder reaches 730,492 $\mathrm{N}$ as the Reynolds number reaches $5.69^{\star} 10^{7}$. When the spin ratio is 2.5 , the maximum thrust reaches $691,213 \mathrm{~N}$.

\section{OTHER ENVIRONMENTAL WIND SPEED DIRECTIONS}

In this section, the thrust coefficients and thrust forces of the rotating cylinder along the ship's sailing direction are plotted for several cases where the heel angle $(\theta)$ of the environmental wind speed is $0,60,90,120$ and 180 degrees, respectively. The results are shown in Fig. 13(a) and Fig. 13(b).

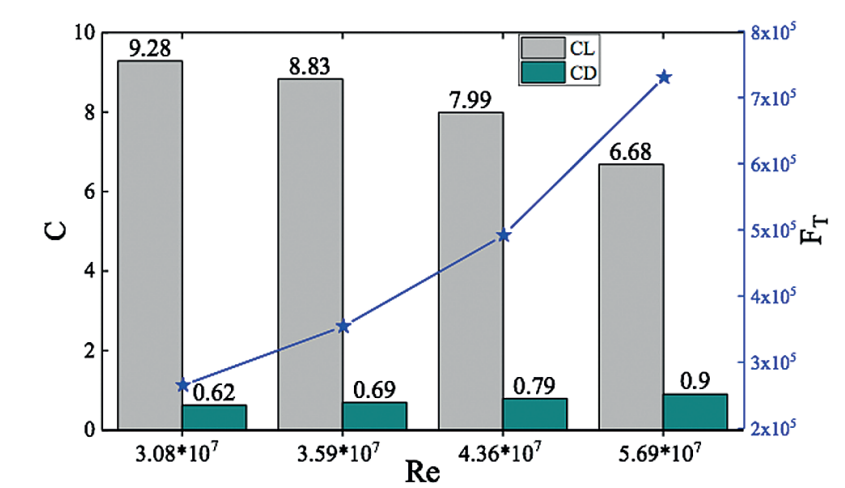

(a) $\alpha=1.5$

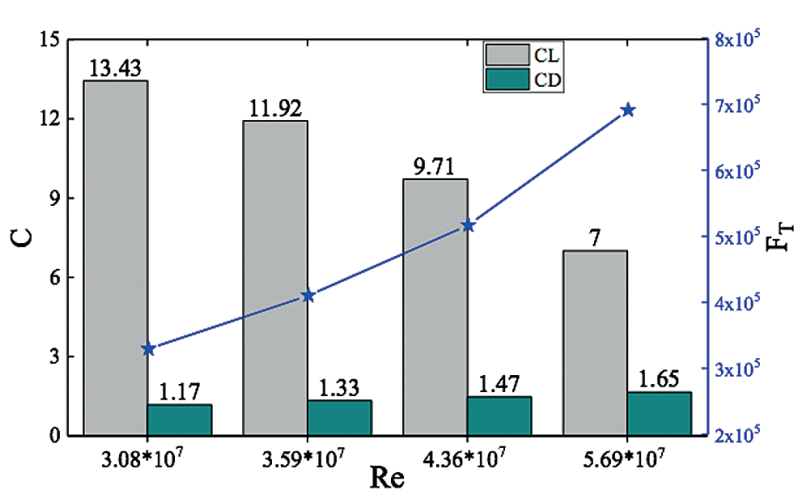

(a) $\alpha=2.5$

Fig. 12. The lift, drag coefficient and thrust values of the rotating cylinder under different Reynolds number 
Specifically, the ship's speed is maintained at $5 \mathrm{~m} / \mathrm{s}$ and the environmental wind speed is the more common 5-level wind, $10 \mathrm{~m} / \mathrm{s}$. When the heel angle is 0 and 180 degrees, the spin ratio of the cylinder is 0 ; in other cases, the spin ratio is taken to be 2.0 .

From Fig. 13, we can see that the thrust coefficient and thrust force are different for different wind directions under the same value of environmental wind. When the heel angle of environmental wind is $0^{\circ}$, the ship is sailing upwind and the thrust coefficient is -0.66 . The thrust is also negative, which is normal. When $\theta=120^{\circ}$, the thrust coefficient reaches its maximum value of 12.7. However, the maximum value of thrust is $311,233 \mathrm{~N}$ when the heel angle is $90^{\circ}$. Similarly, the thrust coefficient and the thrust of the rotating cylinder show a trend of increasing and then decreasing with the increase of the heel angle of the environmental wind. In addition, when $\theta=180^{\circ}$ (i.e. the ship is sailing downwind and the device is not rotating), the cross section of the cylinder can be regarded as a traditional sail and its thrust coefficient is 0.55 , which is smaller compared to the rotating cylinder. This also proves the advantages of the Flettner rotor in ship propulsion.

\section{CONCLUSIONS}

This research proposes a new type of rotating cylinder and its installation method: the superstructure and Flettner rotor are combined organically, which creates a rotating cylinder installed on the superstructure. The Magnus force generated by the Magnus effect provides part of the thrust of the ship. A ship model with a rotating cylinder outside the superstructure is established and related simulations are carried out to obtain the performance of the new rotating cylinder under different wind levels and different spin ratios. Simulations show that the new rotating cylinder has a significant effect and it can produce greater thrust power. Specifically, a typical ship was chosen (a 100,000 ton oil tanker) and the rotating cylinder with a diameter of $40 \mathrm{~m}$ was designed. Through numerical simulation, the maximum effective power that the new rotating cylinder can provide is about $2,240 \mathrm{~kW}$. The specific conclusions are as follows:

1. By comparing and discussing the force coefficient and surrounding pressure of the traditional superstructure, cylindrical superstructure, and rotating cylinder superstructures, it was found that, under the three equal volume conditions, the traditional superstructure and the cylinder superstructure have friction, and the cylinder superstructure has a certain effect on reducing wind drag compared to a traditional design. It is worth noting that the rotating cylinder has the Magnus effect, which generates thrust for the ship.

2. The lift and thrust coefficients of the rotating cylinder under different wind levels are compared. There are inflection points of the lift coefficient and the thrust coefficient as the spin ratio increases. The inflection points of different wind levels correspond to different spin ratios; this indicates that both the wind speed around the rotating cylinder and the spin ratio will have a direct impact on the boosting effect of the rotating cylinder. When the wind level is 5 and the spin ratio is 2.5 , the thrust coefficient reaches its maximum, which is 8.63 . In addition, as the spin ratio increases, the drag coefficient and the heel coefficient generally tend to increase.

3. When comparing the pressure around the rotating cylinder with different spin ratios at the level 6 wind condition, it can be seen that the pressure changes with the change of the spin ratio. At the spin ratio equal to 2.0, the maximum difference of the contour appears to be $900.3 \mathrm{~Pa}$ in Fig 9.

4. Under the same spin ratio conditions, the greater the environmental wind speed, the greater the thrust contribution generated by the rotating cylinder. With an increase in the wind level, the thrust corresponding to the spin ratio equal to 1.5 and 2.0 shows a greater steepness of rise. Under the level 8 wind condition, the thrust of the two reaches their maximum, exceeding 750,000 N. In addition, it is not that a larger spin ratio contributes more to the thrust of the corresponding rotating cylinder. On the

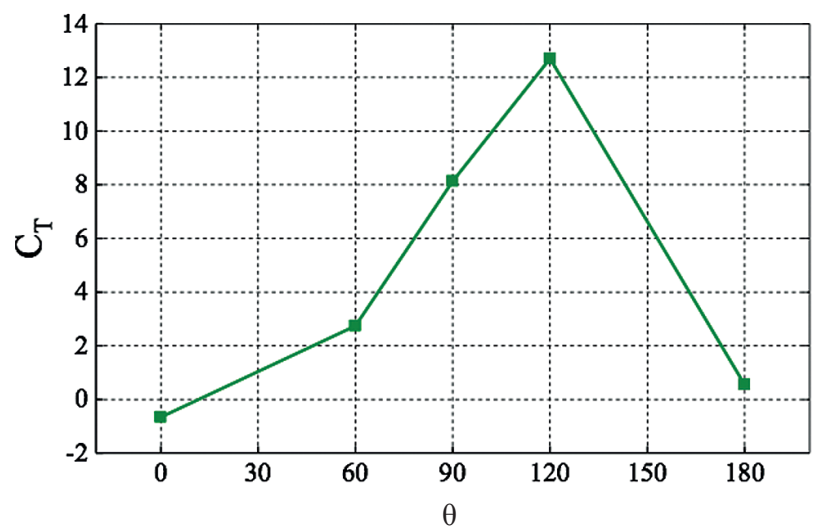

(a)

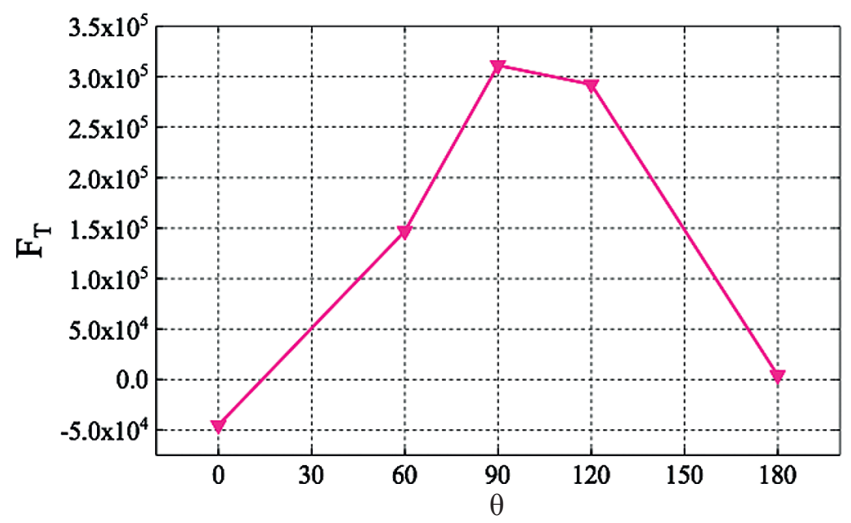

(b)

Fig. 13. The thrust coefficient and thrust of the rotating cylinder for other environmental wind speed directions 
contrary, when the spin ratio is 2.0 , the rotating cylinder shows a better advantage.

5. As the spin ratio increases, the thrust power of the rotating cylinder first increases and then decreases. Higher wind levels correspond to higher thrust power peaks. In addition, the spin ratios corresponding to the maximum effective power under the four wind levels are different: the maximum effective power of the level 8 wind is the largest and the corresponding spin ratio is 1.0; the other three spin ratios are 1.5. It is worth noting that when the maximum effective power appears, the effective power of the rotating cylinder can reach about 75 to $85 \%$ of the thrust power it generates. This also shows that the contribution of the rotating cylinder to the navigation of the ship is far greater than the power consumed by its own rotation.

6. After comparing the influence of the Reynolds number on the force coefficient and thrust of the new rotating cylinder, it was found that: when the Reynolds number increases, the lift coefficient of the rotating cylinder decreases, and the drag coefficient increases; the ship thrust curve shows an upward trend. In addition, the thrust coefficient and thrust force are different for different wind directions under the same value of environmental wind from Fig. 13.

The object of this research is a rotating cylinder installed on the superstructure of a ship. Simulations mainly verified the influence of several common wind levels and spin ratios on the new rotating cylinder. The results proved that there is a good feasibility for the installation of the new rotating cylinder on ships. The research can provide a theoretical basis for later engineering experiments and installation.

\section{ACKNOWLEDGEMENTS}

This work was supported by the National Science Foundation of China (Grant No. 61572404) and Tsinghua University's Shuimu Scholar Program (2020SM027).

\section{REFERENCES}

1. L. Zhen, Y. W. Wu, S. A. Wang, et al. 'Green technology adoption for fleet deployment in a shipping network'. Transportation Research Part B: Methodological, 139 (2020), 388-410.

2. A. Halff, L. Younes, T. Boersma. 'The likely implications of the new IMO standards on the shipping industry'. Energy Policy, 126 (2019), 277-286.

3. Y. P. Yuan, J. X. Wang, X. P. Yan, et al. 'A review of multienergy hybrid power system for ships'. Renewable and Sustainable Energy Reviews, 132 (2020), 110081.

4. P. Cheng, N. Liang, R. Y. Li, et al. 'Analysis of Influence of Ship Roll on Ship Power System with Renewable Energy’. Energies 2020, 13, 1, doi:10.3390/en13010001.

5. Y. Y. Xie, W. Q. Guo, Q. W. Wu, et al. 'Robust MPC-based bidding strategy for wind storage systems in real-time energy and regulation markets'. Electrical Power and Energy
Systems, 124 (2021), 106361.

6. Y. Wang. 'The working principle and practical application of rotor sail'. Shanghai Energy Conservation, 2018 (11), doi:10.13770/j.cnki.issn2095-705x.2018.11.010.

7. L. Talluri, D.K. Nalianda, E. Giuliani. 'Techno economic and environmental assessment of Flettner rotors for marine propulsion'. Ocean Engineering, 154 (2018), 1-15.

8. K. Roncin, M. Behrel, P. Iachkine, et al. 'Benchmark Sea Trials on a 6-Meter Boat Powered by Kite'. Applied Science, 2020, 10, 6148; doi:10.3390/app10186148.

9. R. H. Lu and J. W. Ringsberg. 'Ship energy performance study of three windassisted ship propulsion technologies including a parametric study of the Flettner rotor technology'. Ships and Offshore Structures, doi: 10.1080/17445302.2019.1612544.

10. G. Bordogna, S. Muggiasca, S. Giappino, et al. 'Experiments on a Flettner rotor at critical and supercritical Reynolds numbers. Journal of Wind Engineering \& Industrial Aerodynamics, 188 (2019), 19-29.

11. A. De Marco, S. Mancini, C. Pensa, et al. 'Flettner Rotor Concept for Marine Applications: A Systematic Study'. International Journal of Rotating Machinery, doi:10.1155/2016/3458750.

12. A. De Marco, S. Mancini, C. Pensa, et al. 'Marine application of Flettner rotors: numerical study on a systematic variation of geometric factor by DOE approach', in Proceedings of the 6th International Conference on Computational Methods in Marine Engineering (MARINE'15), Rome, Italy, June 2015.

13. A. Thom. 'Effects of discs on the air forces on a rotating cylinder,' Reports \& Memoranda 1623, Aerospace Research Council, 1934.

14. G. Bordogna, S. Muggiasca, S. Giappino, et al. 'The effects of the aerodynamic interaction on the performance of two Flettner rotors'. Journal of Wind Engineering \& Industrial Aerodynamics, https://doi.org/10.1016/j.jweia.2019.104024.

15. S.J. Karabelas, B.C. Koumroglou, C.D. Argyropoulos, et al. 'High Reynolds number turbulent flow past a rotating cylinder'. Applied Mathematical Modelling, 36 (2012), 379-398.

16. T. Craft, N. Johnson, B. Launder. 'Back to the Future? A Re-examination of the Aerodynamics of Flettner-Thom Rotors for Maritime Propulsion. Flow Turbulence Combust, doi: 10.1007/s10494-013-9486-4.

17. M. Traut, P. Gilbert, C. Walsh, et al. 'Propulsive power contribution of a kite and a Flettner rotor on selected shipping routes'. Applied Energy, 113 (2014), 362-372.

18. S. Salter, G. Sortino, J. Latham. 'Sea-going hardware for the cloud albedo method of reversing global warming. Phil. Trans. R. Soc. A, (2008), 366, 3989-4006, doi:10.1098/ rsta.2008.0136.

19. C. Badalamenti, S. A. Prince. 'Effects of endplates on a rotating cylinder in crossflow', in Proceedings of the 
26th AIAA Applied Aerodynamics Conference, Honolulu, Hawaii, USA, August 2008.

20. F. Tillig, J. W. Ringsberg, et al. 'Design, operation and analysis of wind-assisted cargo ships'. Ocean Engineering, 211 (2020), 107603.

21. X. Y. Lu. 'Study on aerodynamic Performance of Vertical Magnus Wind Turbine'. University of Xiang Tan, May 2019.

22. A. Sedaghat, I. Samani, M. Ahmadi-Baloutaki, et al. 'Computational study on novel circulating aerofoils for use in Magnus wind turbine blades’. Energy, 91 (2015), 393-403.

23. A. Sedaghat. 'Magnus type wind turbines: Prospectus and challenges in design and modelling. Renewable Energy, 62 (2014), 619-628.

24. J. Seifert. 'A review of the Magnus effect in aeronautics'. Progress in Aerospace Sciences, 55 (2012), 17-45.

25. X. Y. Liu, Y. X. Wang, J. J. Liang et al. 'CFD Analysis of Aerodynamic Characteristics of Ship's Wind-Assisted Rotor Sail. Navigation of China', doi: 1000-4653 (2019) 04 -0046-05.

26. G. Dong, P. T. Lee. 'Environmental effects of emission control areas and reduced speed zones on container ship operation' Journal of Cleaner Production, https://doi.org/10.1016/j. jclepro.2020.122582.

27. N. R. Ammar, I. S. Seddiek. 'Enhancing energy efficiency for new generations of containerized shipping'. Ocean Engineering, 215 (2020), 107887.

28. D. Wang, P. L.-F. Liu. 'An ISPH with $\mathrm{k}-\varepsilon$ closure for simulating turbulence under solitary waves'. Coastal Engineering, 157 (2020), 103657.

29. B. J. Guo, S. Steen. 'Comparison of numerical methods for wave generation by VOF-based numerical wave tank. Proceedings of the ASME 2011 30th International Conference on Ocean, Offshore and Arctic Engineering. OMAE 2011-49777.

30. D. Moreira, N. Mathias, T. Morais. 'Dual flapping foil system for propulsion and harnessing wave energy: A 2D parametric study for unaligned foil configurations. Ocean Engineering, 215 (2020), 107875.

31. M. Terziev, T. Tezdogan, A. Incecik. 'Modelling the hydrodynamic effect of abrupt water depth changes on a ship travelling in restricted waters using CFD'. Ships and Offshore Structures, doi: 10.1080/17445302.2020.1816731.

32. I. Razgallah, S. Kaidi, H. Smaoui, et al. 'The impact of free surface modelling on hydrodynamic forces for ship navigating in inland waterways: water depth, drift angle, and ship speed effect.' Journal of Marine Science and Technology, https://doi.org/10.1007/s00773-018-0566-y.

33. D. J. Wang, K. Liu, P. Huo, et al. 'Motions of an unmanned catamaran ship with fixed tandem hydrofoils in regular head waves. Journal of Marine Science and Technology, https:// doi.org/10.1007/s00773-018-0583-X.

34. B. S. Zhang, B. W. Song, Z. Y. Mao, et al. 'Hydrokinetic energy harnessing by spring-mounted oscillators in FIM with different cross sections: From triangle to circle. Energy, 189 (2019), 116249

\section{CONTACT WITH THE AUTHORS}

\author{
Baoshou Zhang \\ e-mail:sxsdzbs@126.com \\ School of Aerospace Engineering \\ Tsinghua University \\ Beijing 100084 \\ China \\ BOYANG LI \\ e-mail:qdlby@126.com
}

College of Electromechanical Engineering Qingdao

University of Science and Technology Qingdao, 266061 Shandong

China

$$
\begin{gathered}
\text { RuI ZHANG } \\
\text { e-mail: qustzr@163.com }
\end{gathered}
$$

College of Electromechanical Engineering Qingdao

University of Science and Technology Qingdao, 266061 Shandong

China

YAJING LI

e-mail: sdliyajing@126.com

College of Electromechanical Engineering Qingdao University of Science and Technology Qingdao, 266061 Shandong

China

\author{
Chao Guo \\ e-mail: sdqdgc@126.com
}

College of Electromechanical Engineering Qingdao University of Science and Technology Qingdao, 266061 Shandong

China 